\title{
A Novel Approach of Friction Stir Cladding of Aluminum on Carbon Steel Plate; Experimental Investigation and Material Characterization
}

\section{Mohammad Mostafa Khalili}

School of Mechanical Engineering, College of Engineering, University of Tehran

Mohammadreza Farahani ( $D$ Mrfarahani@ut.ac.ir)

School of Mechanical Engineering, College of Engineering, University of Tehran

\section{Ali Zohrehvand}

School of Mechanical Engineering, College of Engineering, University of Tehran

Ahmad Aminzadeh

Department of Mathematics, Computer Science and Engineering, Université du Québec à Rimouski, Rimouski, Québec, Canada

\section{Research Article}

Keywords: Friction Stir Cladding, Aluminum Alloys, Carbon Steel, Mechanical characterization

Posted Date: June 12th, 2021

DOI: https://doi.org/10.21203/rs.3.rs-578744/v1

License: (-) (1) This work is licensed under a Creative Commons Attribution 4.0 International License. Read Full License 


\section{Abstract}

Cladding is usually used to improve the material functionality (i.e. corrosion, wear, and oxidation) and to improve the mechanical and thermal properties of the components in different industries. In this study, a new cladding approach based on the friction stir processing was successfully employed on carbon steel plate with 6061-T6 Aluminum alloy. The mechanical and metallurgical properties of the cladding layer were examined at different process parameters. Metallurgical investigation of ST/Al interface was also evaluated using the Scanning electron microscope (SEM) and Optical microscope (OM). Two alloys were mixed uniformly together in the proper process conditions. Based on the results, the decrease of rotational speed from $1200 \mathrm{rpm}$ to $800 \mathrm{rpm}$ at a constant traverse speed of $15 \mathrm{~mm} / \mathrm{min}$, the cladding strength increased from $3.7 \mathrm{KN}$ to $4.8 \mathrm{KN}$. At constant rotational speed of $800 \mathrm{rpm}$, with an increase in traverse speed from $15 \mathrm{~mm} / \mathrm{min}$ to $35 \mathrm{~mm} / \mathrm{min}$, the cladding strength increased from $4.8 \mathrm{KN}$ to $6.6 \mathrm{KN}$.

\section{Introduction}

Friction stir process is a technique for building composite surfaces and modifying the microstructural properties [13]. For the first time, Mishra and Ma In 1991 devised a process that is based on the friction stir welding [4]. In friction stir welding, a circular tool consisting of a shoulder and a pin are located at the joint surface of two base metals and penetrate into the base material until the surface of the tool shoulder engages with the surface of base metal [5] then it rotates and moves along the connecting line [4, 6]. Among the alloys of aluminum, the 6061-T6 alloy is widely used in the industries [7]. A friction-stir welding nowadays is used successfully in the industry for aircrafts, cars and ships $[8,9]$. Due to lower energy consumption than the traditional method of fusion welding and the lower heat affecting on the base metal [10]. Tool parameters can also have a great influence on the material flow and the heat production. The major part of the heat generated in this method is due to the friction between the shoulder and the work-piece. Based on the literature, the share of the pin in total produced heat is low and about 20\% [11]. Xiong et al. studied the lap welding of aluminum-alloy to stainless steel with the friction-stir welding process [12]. Mechanical interlocks due to the flash of the lower layer of steel into the upper aluminum layer around the weld, improve the joint strength. Increasing the depth of the pin penetration in the hard steel layer increases the bond strength, but with increasing the pin penetration depth in steel, the pin wear is increased [13]. In order to improve the mechanical and metallurgical properties a novel method, cladding, is applied in various industries, including oil, chemical and marine. In cladding, sheets of metals and alloys which are more resistant to corrosion and abrasion are clad on parts and devices made of ordinary and cheaper metals, in this way pressure vessels, which often have very high thicknesses and weight, are made of simple carbon steels in which the inside area is cladded with an aluminum alloy.

Aluminum-cladded steel provides a combination of excellent properties, such as high corrosion resistance, high strength to weight ratio, high wear resistance, with low cost; so a great effort for to fabricate clad metallic materials with various techniques and methods such as explosive welding [14], extrusion [15] and cold rolling combined with annealing [16]. In the friction-stir welding process, there is no evidence of cracking in the cladded layer, while in the cladded layer with GMAW, several cracks were created at the clad surface [17]. In 2016, Leitao et al. studied the lap welding of aluminum-to-steel alloy using a multistage friction-stir welding method. It was found that due to the depth of penetration of the pin in the lower steel layer, the region affected by thermomechanical operations in the steel layer was very low, while the affected zone in the aluminum layer due to the high heat input created by multipass stages are very high [18]. In 2016, Shen et al. studied the lap welding of stainless-steel ST-316 to aluminum 6061 using a zinc-alloy interlayer, and with the help of the friction-stir welding process. They concluded that zinc metal was widely spread in aluminum, it was also noticeable that zinc spread more on the retreating side in comparison to the advancing side [19]. In 2016, the titanium alloys with pure aluminum were cladded up with the help of the new process of friction-stir welding. The effect of the process variables and thermal treatment on the bonding behavior 
was investigated. It was determined that the thermal-mechanical effect of friction-stir welding was the main bonding mechanism of Aluminum to Titanium [20].

To the best of the authors' knowledge, there is no study on cladding the surface of ST-37 steel with aluminum 6061T6 has been investigated using a new friction stir process; further, the mechanical and metallurgical characterization have been considered. The study showed that the friction stir technique can be used as a new method in the development of low-cost, high performance multi-layer sheet production.

\section{Materials And Methods}

In this research, aluminum alloy 6061-T6 was used as resistance layer on the ST-37 steel. This alloy has excellent corrosion resistance in the atmospheric environment and good corrosion resistance in industrial and marine areas [7]. This alloy is used as a cladding for the ST37 steel surface. The chemical composition and mechanical properties of aluminum alloy 6061-T6 and ST47 are shown in Table 1 and Table 2, respectively. A $10 \times 100 \times 150 \mathrm{~mm}$ St37 steel sheet was used in this study. The 6061-T6 aluminum sheet with $2 \mathrm{~mm}$ thickness was used as cladding on the steel sheet. All the specimens were cut with wire-cut machine.

Table 1

Chemical composition of the

\begin{tabular}{|lllllllllllllll|}
\hline Material & Al & Mg & Mn & Zn & Fe & Cu & Si & Cr & Ti & C & S & P & Mn & Fe \\
\hline $\begin{array}{l}\text { AL } \\
\text { 6061- }\end{array}$ & Bal & 0.84 & 0.15 & 0.25 & 0.7 & 0.24 & 0.54 & 0.18 & 0.15 & - & - & - & - \\
T6 & & & & & & & & & & & & & \\
ST37 & & - & - & - & - & - & - & - & - & 0.17 & 0.05 & 0.45 & 1.14 & Bal \\
\hline
\end{tabular}

Table 2

Mechanical properties of the

\begin{tabular}{|lllll|}
\hline Material & $\begin{array}{l}\text { Yield Strength } \\
(\mathbf{M P a})\end{array}$ & $\begin{array}{l}\text { tensile Strength } \\
(\mathbf{M P a})\end{array}$ & $\begin{array}{l}\text { Elongation } \\
(\%)\end{array}$ & $\begin{array}{l}\text { Hardness } \\
(\mathbf{H V})\end{array}$ \\
\hline AL 6061-T6 & 240 & 290 & 9 & 85 \\
\hline ST37 & 235 & 350 & 17 & 130 \\
\hline
\end{tabular}

In this study, the 6061-T6 aluminum sheet was placed at the top of the St37 steel. As shown in Fig. 1, the nonconsumable tool has three rotational, traverse and vertical moves for the penetration into the work surface; with the rotational and vertical forces, the tool penetrates into work surface. After a first pause to generate heat and form a paste material, the tool moves along a straight line. Due to the fact that the friction-stir cladding (FSC) process is carried out in several passes adjacent to each other, the depth of penetration of the tool plays a major role in the uniformity of the surface, especially in the middle layer of the Al/St. The tool has three functions in the FSC process: The first is heating the work-piece through the pin and shoulder friction and plastic deformation of the materials, the second is creating the material flow for connecting the two materials, and the third is limiting the hot metal under the tool shoulder. The tool may be exposed to abrasion due to the contact with the workpiece at high temperature, so the tool should be selected based on the hardness of the work-piece and the process temperature; in this research, a nonconsumable tool was used from tungsten carbide, which is positioned at an angle of 3 degrees to the vertical axis. The geometry of the employed tool and its geometric dimensions are shown in Fig. 1b. Xiong et al. also used similar geometry for friction-stir welding of aluminum-steel plates [12]. Tool geometry and its dimensions are some of the 
most important variables in the friction-stir welding process [21]. A tool with conical, pin with small and large diameters of 4 and $6 \mathrm{~mm}$, pin height of $2.15 \mathrm{~mm}$ and $20 \mathrm{~mm}$ shoulder diameter, was employed in this study.

The cladding input heat is the most important factor which changes the structure and mechanical properties of the connection. Heat input has a direct relation to the rotational speed and has an inverse relationship with the traverse speed. The penetration depth determines the amount of penetration of the shoulder into the aluminum layer and the penetration of the pin into the steel layer so the considered parameters in this study are the speed of rotation, traverse speed and penetration depth. Various Rotational (RS) and Traverse Speeds (TS) studied in this paper are listed in Table 3. The milling machine used to perform the friction-stir cladding in this study and cladding setup are shown in Fig. 3.

Table 3

Friction stir cladding process parameters

\begin{tabular}{|lll|}
\hline Process no. & $\begin{array}{l}\text { Traverse speed } \\
\text { (mm/min) }\end{array}$ & $\begin{array}{l}\text { Rotational speed } \\
\text { (rpm) }\end{array}$ \\
\hline 1 & 15 & 800 \\
2 & 25 & 800 \\
3 & 35 & 800 \\
4 & 15 & 1000 \\
5 & 25 & 1000 \\
6 & 35 & 1000 \\
7 & 15 & 1200 \\
8 & 25 & 1200 \\
9 & 35 & 1200 \\
\hline
\end{tabular}

The mechanical properties of the specimens fabricated by the friction-stir cladding were evaluated by shear test at ambient temperature. For the shear test, two shear test specimens were prepared from each sample. The square shear test specimens were fabricated with an edge length of $10 \mathrm{~mm}$ which was cut by the wire-cut machine. In order to perform the shear test, a fixture from $\mathrm{H} 13$ high strength steel was fabricated by machining with high in accuracy and surface quality. The fixture image used to perform the shear test and the shear test specimen are shown in Fig. 3. The test speed for all specimens was $1 \mathrm{~mm} / \mathrm{min}$. The results of the two specimens were very close to each other and only $5 \%$ differences was observed. In the following, the average strength of both specimens was presented.

After the friction-stir cladding process, for analyzing the material flow and material structure in the middle layer of aluminum and steel, specimens with the appropriate size of the sheet cross section were cut by a wire-cut machine; these specimens are also shown in Fig. 4. The surface of the specimens with sandpaper numbers of $80,120,400$, $600,800,1000,1500,2000,3000$, was finished and then polished. The specimens were evaluated by an optical microscope. In order to examine the intermediate layer more precisely a scanning electron microscope (SEM) was also used. In this study, the VEGA/TESCAN-XMU scanning electron microscope was used. EDS and Line Scanning were used for the determination of the chemical composition of the intermediate layer of the cladding specimens and material mixing in the middle layer. 


\section{Results And Discussion}

\subsection{Adjustment of penetration depth to form the middle layer bond}

Plastic deformation and temperature increase in the weld region led to a dynamic re-crystallization and microstructure changes, dissolution and coarsening of the region around the joint. Accordingly, three different regions called stir zone (SZ), the thermo-mechanically affected zone (TMAZ) and the heat affected zone (HAZ) are recognizable. Because of the severe plastic deformation and the sudden increase in temperature of the stir zone, the grains are broken up and the grain boundaries are created with low angles [22]. These locations are suitable places for germination. Then, recrystallization occurs which create a fine-grained structure in the stir zone. As well, the amount of alloying elements in aluminum 6061-T6 is effective on the grain size. Alloy elements cause the formation of deposits in the weld zone. The presence of precipitation in the stir zone can act as a grain growth barrier.

The depth of penetration of the tool in the aluminum layer is one of the important parameters in the friction-stir cladding process. The penetration depth of the tool determines the amount of pin penetration in the steel layer and the penetration of the shoulder into the aluminum layer. The tool penetration depth affects the quality of the sheet surface and the material flow under the shoulder. By increasing the tool penetration depth, the tool cladding forging pressure increases as well. The excessive penetration depth of the shoulder in the aluminum layer causes high pressure and high heat input, and as a result the adhesion of the material to the shoulder surface, contuse of connection surface, material deflection and joint weakness. In Fig. 4(a), the penetration depth (PD) is $0.25 \mathrm{~mm}$. applicable penetration depth of $0.1 \mathrm{~mm}$ was selected in this study by visual inspection. Which resulted in minimizing the chip formation, the uniform surface of the cladding and proper applied heat on the steel layer. The specimen obtained from the penetration depth of $0.1 \mathrm{~mm}$ is shown in Fig. 4(b). Continuing this study, a constant $0.1 \mathrm{~mm}$ penetration depth was used for all specimens.

The stir behavior of the tool pins in the middle layer has a great influence on the characteristics of the multilayer aluminum and steel structures produced by the friction-stir method. Pin implications include severe plastic deformation and mechanical mixing of aluminum and steel alloys in the middle layer of Al/St. The frictional behavior of the pin in the middle layer has a significant effect on ensuring the mixing of materials in the middle layer. The heat generated to form the middle layer of aluminum and steel mainly consists of three mechanisms a) contact of the shoulder with the surface of the aluminum sheet, $b$ ) contact of the outer surface of the pin with the aluminum layer and the end surface of the pin with the steel layer, and c) the internal heat of the material released due to severe plastic deformation, created by pin cutting. According to the Fig. 5, an optical microscope image is used from the cross section of a cladded specimen at a rotational speed of $800 \mathrm{rpm}$ and a traverse speed of $25 \mathrm{~mm} / \mathrm{min}$. Besides, Fig. 5(a) shows the location of the pin penetration in the steel layer. In the Al/St bonding line, a dual color zone is formed which confirms that the aluminum and steel are well combined in the middle layer and cause the aluminum layer to be cladded over the steel layer. The pin height is $2.15 \mathrm{~mm}$ and the depth of the shoulder penetration into the aluminum layer is $0.1 \mathrm{~mm}$. Thus, only $0.25 \mathrm{~mm}$ of the pin height penetrates into the lower steel layer and mixes the material. Consequently, the stir zone and bonded area are approximately equal to the small diameter of the pin. Due to the pin penetration into the steel layer, the molded steel parts entered to the aluminum layer, uneven surfaces and the mechanical locking of aluminum and steel in the middle layer. Figure 5(b), (c), (d), (e), (f), (g) show the enlarged areas of the different parts of the middle layer of the Al/St. Due to the penetration of the pin on the steel layer, the middle layer plastic materials are stirred due to the frictional-stir behavior of the pin, with the traverse and rotational movement of the tool, the softened material and the steel particles in the middle layer move up and make hooks. The hooks cause the sheet to be bonded or locked in the middle layer, which strengthen the cladding. 
Figure 6 shows a scanning electron microscope from a cross section of the cladded specimen at a rotational speed of $800 \mathrm{rpm}$ and a traverse speed of $25 \mathrm{~mm} / \mathrm{min}$. Figure 6(a) shows the image of an electron microscope from aluminum and steel layers, which show no evidence of aluminum penetration in the steel layer. Figure 6(b) illustrates the line scanning along the line shown in Fig. 6(a). The thickness of the blended area in the middle layer of Al/St is approximately $150 \mu \mathrm{m}$. The image confirms that a metallurgical bond is formed through the thermal, mechanical effects of the frictional-stir process in the middle layer of aluminum and steel.

In order to more accurately analyze the changes of alloy elements in different regions of the cladded specimens, from the 3 points indicated in Fig. 6(a), EDX analysis is taken as shown in Fig. 6 (c, d, e). The results show that the aluminum compound in the middle layer is considerably larger than the steel.

\subsection{Evaluation of the effect of rotational speed and traverse speed on the cladding process}

Generally, rotational speed and traverse speed are two main parameters in FSW process. The optical microscopic photos of the cross section of cladded specimens with different combinations of traverse and rotational speeds are illustrated in Figs. 7 and 8 . The vertical force of the tool, the rotational speed and the shoulder contact with the upper surface of the sheets create heat, plasticize the materials and extrude them under the shoulder by the moves of the tool into the lower layer of steel. The steel molded parts tool enters to the upper aluminum layer and creates an uneven surface in the middle layer, which improves bonding of the two sheets in the middle layer [23]. It seems that this phenomenon is related to the fluctuations imposed by the tool rotation [24]. By increasing the traverse speed and decreasing the rotational speed, the temperature of the friction-stir cladding process decreases. Since the origin of heat in this method is the friction between the tool and the work-piece, the heat input is directly related to rotational speed and has an opposite relationship with the tool traverse speed. By increasing the traverse speed, the heat source moves faster from each section and hence the heat input into the bonding zone decreases. Reducing the rotational speed reduces the frictional energy and consequently the heat input. In this situation, the oscillations increase during the process, and as a result, uneven material distribution increases in the middle layer and the bond will be strengthened. The temperature in the friction-stir cladding process is one of the most effective parameters, which is usually asymmetrical. The temperature on the advancing side is much higher than the retreating side [19].

Figure 7(a), (b) shows the cross-section area of the cladded specimen at a rotational speed of $1200 \mathrm{rpm}$ and a traverse speed of $35 \mathrm{~mm} / \mathrm{min}$. Figure 7(a) has a magnification of 50 times as can be seen, due to the penetration of the pin in the steel layer, uneven surfaces have been created in the middle layer which improve connection and the mechanical bonding of the aluminum and steel sheets in the middle layer. Figure 7(b) illuminates 500 times magnification which clearly presents the molded parts of the steel which was inserted into the aluminum region. Figure 7(c), (d) shows the cross-sectional area of the cladded specimen at a rotational speed of $1000 \mathrm{rpm}$ and a traverse speed of $35 \mathrm{~mm} / \mathrm{min}$. The mixing of aluminum and steel sheets in the middle layer is quite obvious, which is similar to that of explosive welding [25], with a reduction of rotational speed from $1200 \mathrm{rpm}$, to $800 \mathrm{rpm}$, the heat produced during the movement of the tool decreased, resulting in reduced cladding temperature. The lower temperature of the connection zone has led to more severe plastic deformation during the cladding process. These severe plastic deformations lead to further fluctuations in the middle layer, strongly dispersing the steel particles on the aluminum layer, which result in better binding and bonding of the two metals.

Fig. 8 compares the cross-sectional area of the cladded specimen rotational speeds of $800 \mathrm{rpm}$, at traverse speed of $35 \mathrm{~mm} / \mathrm{min}$ Fig. 8(a, b), and $15 \mathrm{~mm} / \mathrm{min}$ Fig. 8(c, d). By increasing the traverse speed from $15 \mathrm{~mm} / \mathrm{min}$, to 35 
$\mathrm{mm} / \mathrm{min}$, the interface materials were well-integrated due to the higher forging force, and consequently stronger mechanical bond was formed.

Figure 9 shows an image of the optical and scanning electron microscope of a cross section of a cladded specimen at a rotation speed of $1000 \mathrm{rpm}$ and a traverse speed of $25 \mathrm{~mm} / \mathrm{min}$.

Based on the results, the broken particles of steel that are diffused in the aluminum layer due to the frictional-stir behavior of the cross section of the SEM images, there is no evidence of cracks or porosity. More specifically, Figs. 9(b, c) show the enlarged areas in Fig. 9(a), which clearly present that the aluminum and steel in the middle layer are well integrated. The tool's friction-stir behavior and its pressure on the soft material in the middle layer result in the downward movement of softened aluminum in hard steel and the upward movement of hard steel in the soft aluminum layer. Extruded and upright movement of hard steel prevents the downward movement of soft aluminum; as shown in Fig. 9(d), there is no trace of soft aluminum penetration in the lower layer of steel. Figure $9(e)$ is a line scanning analysis in the direction shown in Fig. 9(d).

\subsection{The effect of rotational and traverse speed on the bond strength of the cladding}

Factors such as grain size, dislocation density and size and morphology of precipitations of aluminum alloys, effect on the bond strength. The cladding heat input is the most important factor influencing the structure and mechanical properties of the connection. Heat input has a direct relation with rotational speed and an opposing relation to the traverse speed, so that with the increase of the rotational speed and decrease of the traverse speed, frictional heat and temperature increase. Increasing the temperature will increase the grain size and will reduce the joint strength. Higher heat input increases the dissolving and coarsening of the precipitation and decreases the dislocation density. One of the main reasons for reducing the joint strength with increasing the process temperature is the reduction of the forging pressure of the materials under the tool shoulder and consequently the facilitation of the material flow around the pin. Consequently, the severity of plastic deformations in this area was decreased. In addition, at higher temperatures, due to the easy flow of materials, the probability of discontinuities and cavity formation in the bonding zone increases, which can lead to a reduction of bond strength. Failure load was considered to evaluate the strength of cladding. In Fig. 10, the shear strength of the cladded specimen is shown for different rotational and traverse speeds. As shown in Fig. 10, with the decrease of rotational speed from $1200 \mathrm{rpm}$ to $800 \mathrm{rpm}$ at a constant traverse speed of $15 \mathrm{~mm} / \mathrm{min}$, the cladding strength increased from $3.7 \mathrm{KN}$ to $4.8 \mathrm{KN}$. At constant rotational speed of $800 \mathrm{rpm}$, with an increase in traverse speed from $15 \mathrm{~mm} / \mathrm{min}$ to $35 \mathrm{~mm} / \mathrm{min}$, the cladding strength increased from $4.8 \mathrm{KN}$ to $6.6 \mathrm{KN}$. It can be explained by a higher forging force which entered the materials into the joints. As the traverse speed increases, the cladding heat input lowers and the cooling rate increases, which prevents excessive turbulence in the connection. It also stops the grain coarsening at the welding region; in addition, the lower cladding time results in more mechanical work due to the tool stir process. Higher plastic deformation of the material in the joining site at a higher traverse speed increases the joint strength. Due to the extreme plastic deformation and high process temperature, the grains are broken up and grain boundaries with low angles are formed [22]. Dynamic recrystallization occur which creates a more fine-grained structure in the stir zone [26]. Increasing the rotational speed increase the frictional heat and consequently the grain size is increased due to more annealing. As a result, the bond strength decreases with increasing the rotational speed.

In order to determine the effect of traverse speed on surface flow of materials, the line surface of the joints cladded up with the rotational speed of $800 \mathrm{rpm}$ is shown in Fig. 11(a, b, c). As can be seen in this Fig, as the traverse speed increases, the surface quality of the samples improves; more entrance of material from the front of the tool to the stir 
zone, improves the material flow and surface quality $[27,28]$. Figure 11 (c) at low traverse speed of $15 \mathrm{~mm} / \mathrm{min}$ manifests that due to inappropriate forging force, nonuniform entrance of materials into the joints, higher cladding heat input, and excessive turbulences, the cladded surface is rough and uneven.

\subsection{Hardness}

In the heat-treated alloys, the size and distribution of precipitations in these alloys play a more important role in the hardness of these metals in comparison to grain size. Plastic deformation at high cladding temperature leads to a dynamic re-crystallization and dissolution and growth of the precipitations around the region.

In Fig. 12, the hardness value at constant rotational speed of $800 \mathrm{rpm}$ and the different traverse speeds along the thickness from the St37 steel side to the 6061-T6 aluminum were measured. The hardness in the steel gradually increases in the direction of thickness, the hardness in the middle layer of aluminum and steel is maximized. Bang et al. mentioned that the cause of the hardening decrease in the thermal-mechanical working zone, the dissolution of the secondary phase, and the coarsening of the dots are due to the effects of mechanical-thermal work and dynamic recrystallization, and the reduction of hardness in the heat-affected area, possibly is due to the dissolution of the sediments during the welding [29]. It was observed that the hardness increased by decreasing the traverse speed from $35 \mathrm{~mm} / \mathrm{min}$ to $15 \mathrm{~mm} / \mathrm{min}$. The lower traverse speed leads to an increase in the heat input in the bonding area and consequently decreases the hardness. The clad interface has more hardness than the heat affected region, as the clad interface experiences the maximum plastic deformation and the re-crystallization and has the finest grain size by increasing the distance from the interface less probability of the re-crystallization, resulting in a larger grain size and consequently reduction in hardness.

\section{Conclusions}

In this study, the surface of St37 steel was successfully coated by 6061-T6 aluminum using a new friction-stir process cladded, and the effect of rotational and traverse speed on the mechanical properties and cladding microstructure was investigated. The results are summarized as follows:

- The thickness of the Al/St middle layer is approximately $150 \mu \mathrm{m}$ which is highly confirmed forming a metallogenic bond through the thermal-mechanical effects of the friction-stir process in the middle layer of the aluminum and steel.

- By increasing the traverse speed from $15 \mathrm{~mm} / \mathrm{min}$, to $35 \mathrm{~mm} / \mathrm{min}$, the interface materials were well-integrated due to the higher forging force, and consequently stronger mechanical bond was formed.

- By decreasing of rotational speed from $1200 \mathrm{rpm}$ to $800 \mathrm{rpm}$ at a constant traverse speed of $15 \mathrm{~mm} / \mathrm{min}$, the cladding strength increased from $3.7 \mathrm{KN}$ to $4.8 \mathrm{KN}$.

- At constant rotational speed of $800 \mathrm{rpm}$, with an increase in traverse speed from $15 \mathrm{~mm} / \mathrm{min}$ to $35 \mathrm{~mm} / \mathrm{min}$, the cladding strength increased from $4.8 \mathrm{KN}$ to $6.6 \mathrm{KN}$.

- At low traverse speed of $15 \mathrm{~mm} / \mathrm{min}$ manifests that due to inappropriate forging force, nonuniform entrance of materials into the joints, higher cladding heat input, and excessive turbulences, the cladded surface is rough and uneven.

- The cladding interface hardness is higher than the other zones. It was observed that the hardness increased by decreasing the traverse speed from $35 \mathrm{~mm} / \mathrm{min}$ to $15 \mathrm{~mm} / \mathrm{min}$. The lower traverse speed leads to an increase in the heat input in the bonding area and consequently decreases the hardness. 


\section{Declarations}

\section{Funding}

No funding

\section{Conflicts of interest}

The authors declare that they have no known competing financial interests or personal relationships that could have appeared to influence the work reported in this paper.

\section{Availability of data and materials}

The raw/processed data required to reproduce these findings cannot be shared at this time as the data also forms part of an ongoing study.

Code availability

Not applicable

\section{Ethical Approval}

All procedures performed in studies involving human participants were in accordance with the ethical standards.

\section{Consent to Participate}

The corresponding author approves this document on behalf of all the authors.

\section{Consent for Publish}

The corresponding author approves this document on behalf of all the authors.

\section{Authors Contributions}

- Mohammad Mostafa Khalili

Data curation, Methodology, Software, Formal analysis, Writing - original draft

- Mohammadreza Farahani

Methodology, Software, Formal analysis, Writing - original draft

- Ali Zohrehvand

Supervision, review \& editing.

- Ahmad Aminzadeh

Supervision, review \& editing.

\section{References}


[1] John JSP, Shanmuganatan MB, Kiran VS, Kumar S, Krishnamurthy R (2019) Investigation of friction stir processing effect on AA 2014-T6. Materials and Manufacturing Processes 34:159-176

[2] Patel V, Li W, Xu Y (2019) Stationary shoulder tool in friction stir processing: a novel low heat input tooling system for magnesium alloy. Materials and Manufacturing Processes 34:177-182

[3] Kumar KA, Natarajan S, Duraiselvam M, Ramachandra S (2019) Synthesis, characterization and mechanical behavior of Al 3003-TiO surface composites through friction stir processing. Materials and Manufacturing Processes 34:183-191

[4] Mishra RS, Ma ZY(2005) Friction stir welding and processing. Materials Science and Engineering: R: Reports 50:178

[5] Thankachan TK, Prakash S, Kavimani V (2018) Effect of friction stir processing and hybrid reinforcements on copper. Materials and Manufacturing Processes 33:1681-1692

[6] Parikh VK, Badgujar AD, Ghetiya ND (2019) Joining of metal matrix composites using friction stir welding: a review. Materials and Manufacturing Processes 34:123-146

[7] Liu G, Murr L, Niou C, McClure J, Vega F (1997) Microstructural aspects of the friction-stir welding of 6061-T6 aluminum. Scripta Materialia 37:355-361

[8] Bajakke PA, Malik VR, Deshpande AS (2019) Particulate metal matrix composites and their fabrication via friction stir processing - a review. Materials and Manufacturing Processes 34:833-881

[9] Goel P, Khan NZ, Khan ZA, Ahmari A, Gangil N, Abidi MH, Siddiquee AN (2019) Investigation on material mixing during FSW of AA7475 to AISI304. Materials and Manufacturing Processes 34:192-200

[10] Mahoney M, Rhodes C, Flintoff J, Bingel W, Spurling R (1998) Properties of friction-stir-welded 7075 T651 aluminum. Metallurgical and Materials Transactions A 29:1955-1964

[11] Elangovan K, Balasubramanian V (2007) Influences of pin profile and rotational speed of the tool on the formation of friction stir processing zone in AA2219 aluminium alloy. Materials Science and Engineering: A 459:7-18

[12] Xiong JT, Li JL, x Qian JL, Zhang FS, Huang WD (2012) High strength lap joint of aluminium and stainless steels fabricated by friction stir welding with cutting pin. Science and Technology of Welding and Joining 17:196-201

[13] Kimapong K, Watanabe T (2004) Friction stir welding of aluminum alloy to steel. Welding Journal 83:277-282

[14] Asemabadi M, Sedighi M, Honarpisheh M (2012) Investigation of cold rolling influence on the mechanical properties of explosive-welded Al/Cu bimetal. Materials Science and Engineering: A 558:144-149

[15] Lee JS, Son H, Oh I, Kang C, Yum CH, Lim SC, Kwon HC (2007) Fabrication and characterization of Ti-Cu clad materials by indirect extrusion. Journal of Materials Processing Technolgy 187:653-656

[16] Li X, Zu G, Ding M, Mu Y, Wang P (2011) Interfacial microstructure and mechanical properties of Cu/Al clad sheet fabricated by asymmetrical roll bonding and annealing. Materials Science and Engineering: A 529:485-491

[17] Shen Z, Chen Y, Haghshenas M, Nguyen T, Galloway J, Gerlich AP (2015) Interfacial microstructure and properties of copper clad steel produced using friction stir welding versus gas metal arc welding. Materials Characterization 
$104: 1-9$

[18] Leitao C, Arruti E, Aldanondo E, Rodrigues DM (2016) Aluminium-steel lap joining by multipass friction stir welding. Materials \& Design 106:153-160

[19] Zheng Q, Feng X, Shen Y, Huang G, Zhao P (2016) Dissimilar friction stir welding of 6061 Al to 316 stainless steel using $\mathrm{Zn}$ as a filler metal. Journal of Alloys and Compounds 686:693-701

[20] Li B, Shen Y, Luo L, Hu W (2016) Effects of processing variables and heat treatments on Al/Ti-6Al-4V interface microstructure of bimetal clad-plate fabricated via a novel route employing friction stir lap welding. Journal of Alloys and Compounds 658:904-913

[21] Fari A, Batalha GF, Prados EF, Magnabosco R, Delijaicove S (2013) Tool Wear Evaluations In Friction Stir Processing Of Commercial Titanium Ti-6Al-4V. Wear 302:1327-1333

[22] Ma ZY, Mishra RS, Mahoney MW (2002) Superplastic deformation behaviour of friction stir processed 7075AI alloy. Acta Materialia 50:4419-4430

[23] Hammerschmidt M, Kreye H (1981) Microstructure and bonding mechanism in explosive welding. In: Meyers MA, Murr LE (Eds) Shock Waves and High-Strain-Rate Phenomena in Metals,1st ed. Springer, Boston, pp 961-973

[24] Yang B, Yan J, Sutton MA, Reynolds AP (2004) Banded microstructure in AA2024-T351 and AA2524-T351 aluminum friction stir welds: Part I. Metallurgical studies. Materials Science and Engineering: A 364:55-65

[25] Hunt JN (1968) Wave formation in explosive welding. The Philosophical magazine 17:669-680

[26] Humphreys FJ, Prangnell PB, Priestner R (2001) Fine-grained alloys by thermomechanical processing. Current Opinion in Solid State and Materials Science 5:15-21

[27] Mendez PF, Tello KE, Lienert, TJ (2010) Scaling of coupled heat transfer and plastic deformation around the pin in friction stir welding. Acta Materialia 58:6012-6026

[28] Arora A, Zhang Z, Deb A, Debroy T (2009) Strains and strain rates during friction stir welding. Scripta Materialia 61:863-866

[29] Bang H, Bang H, Jeon G, Oh, I, Ro C (2012) Gas tungsten arc welding assisted hybrid friction stir welding of dissimilar materials Al6061-T6 aluminum alloy and STS304 stainless steel. Materials \& Design 37:48-55

\section{Figures}




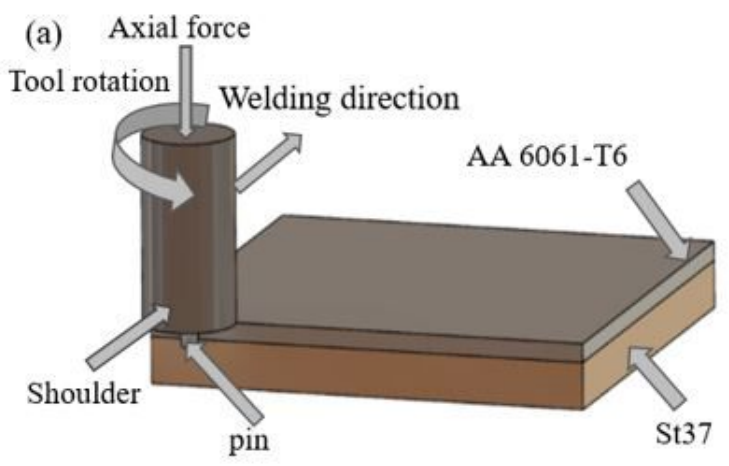

(a)

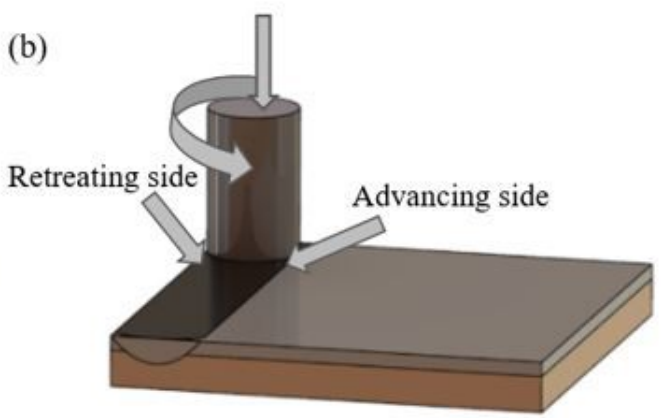

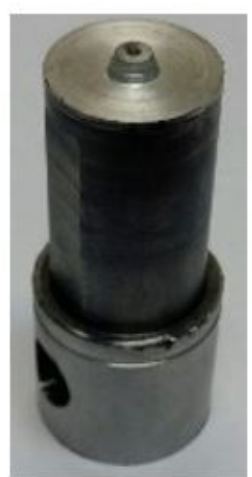

(b)

\section{Figure 1}

Schematic of friction stir cladding
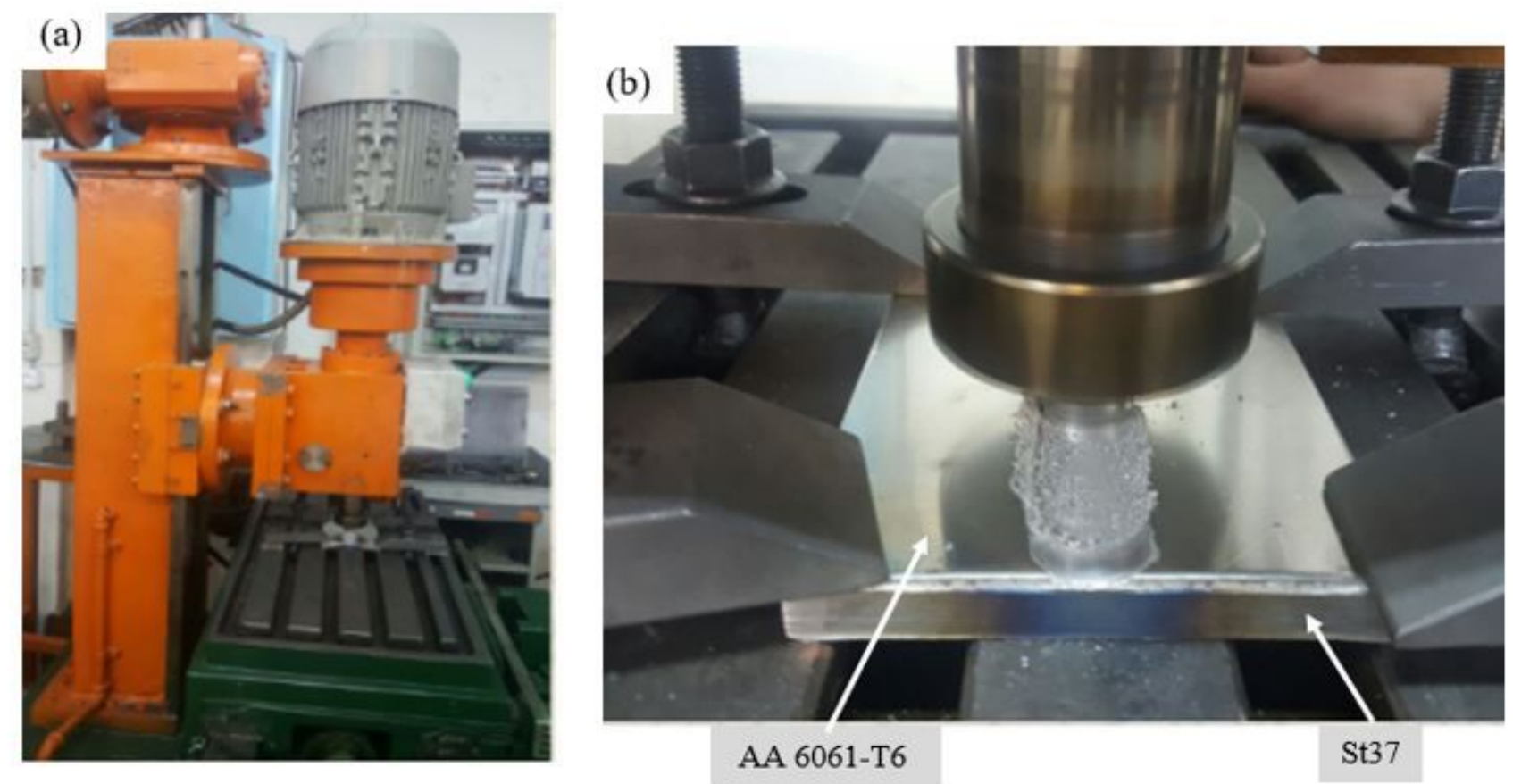

\section{Figure 2}

(a) The cladding setup, (b) Clamping of plates during the process 

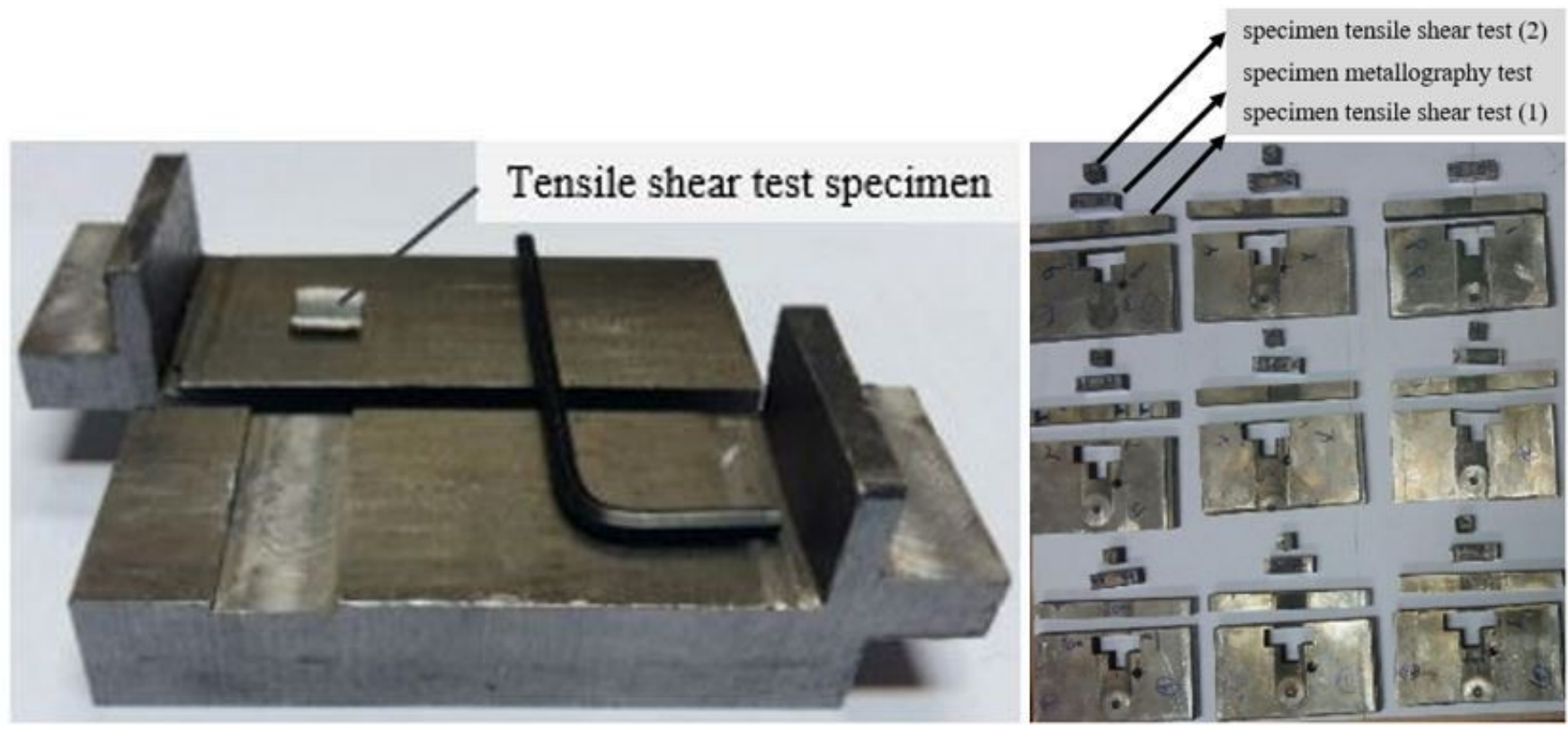

Figure 3

Shear test fixture and hardness test specimens 

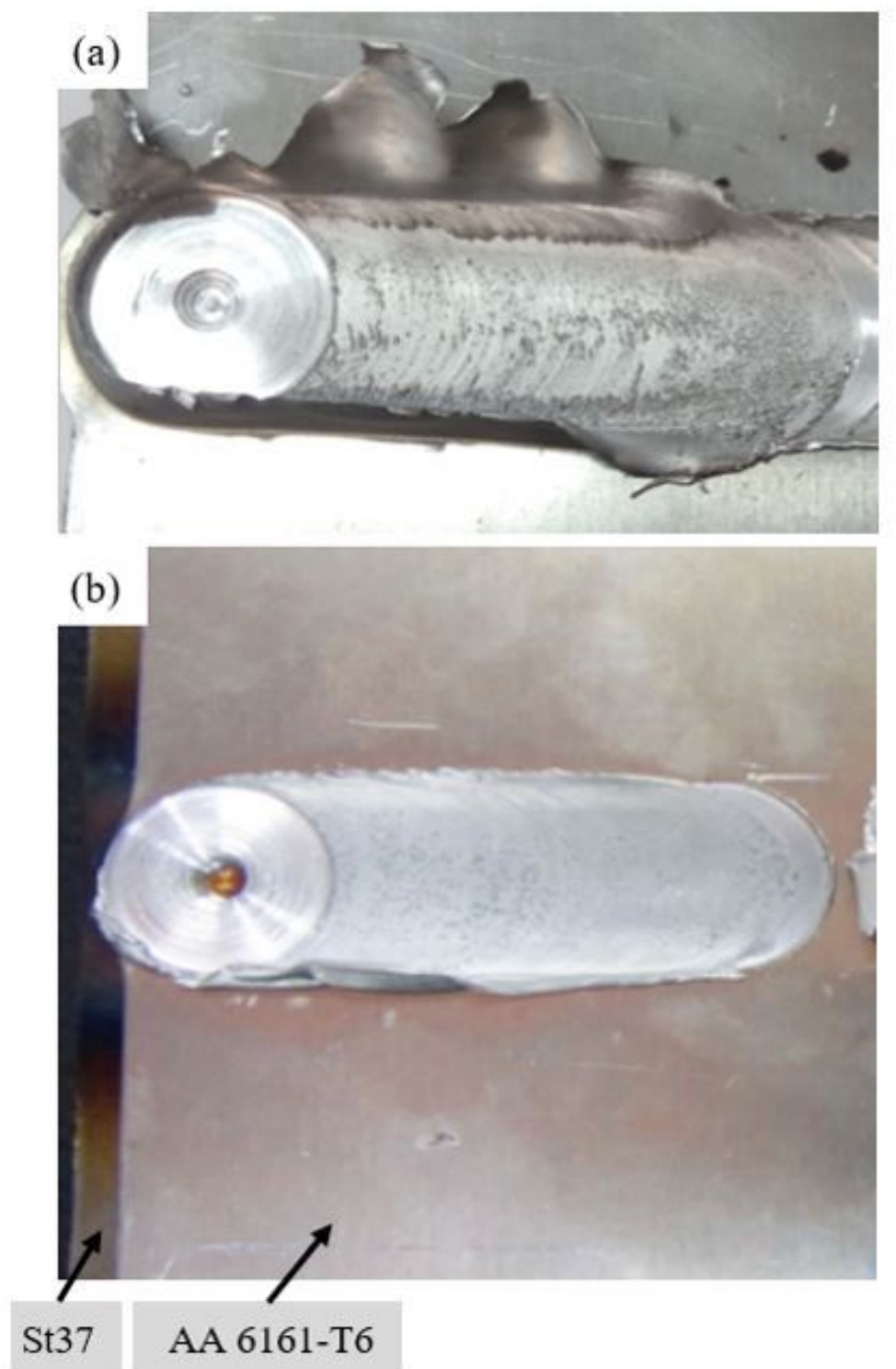

Figure 4

Effect of penetration depth on the cladding, (a) PD of $0.35 \mathrm{~mm}$, (b) PD of $0.1 \mathrm{~mm}$ 


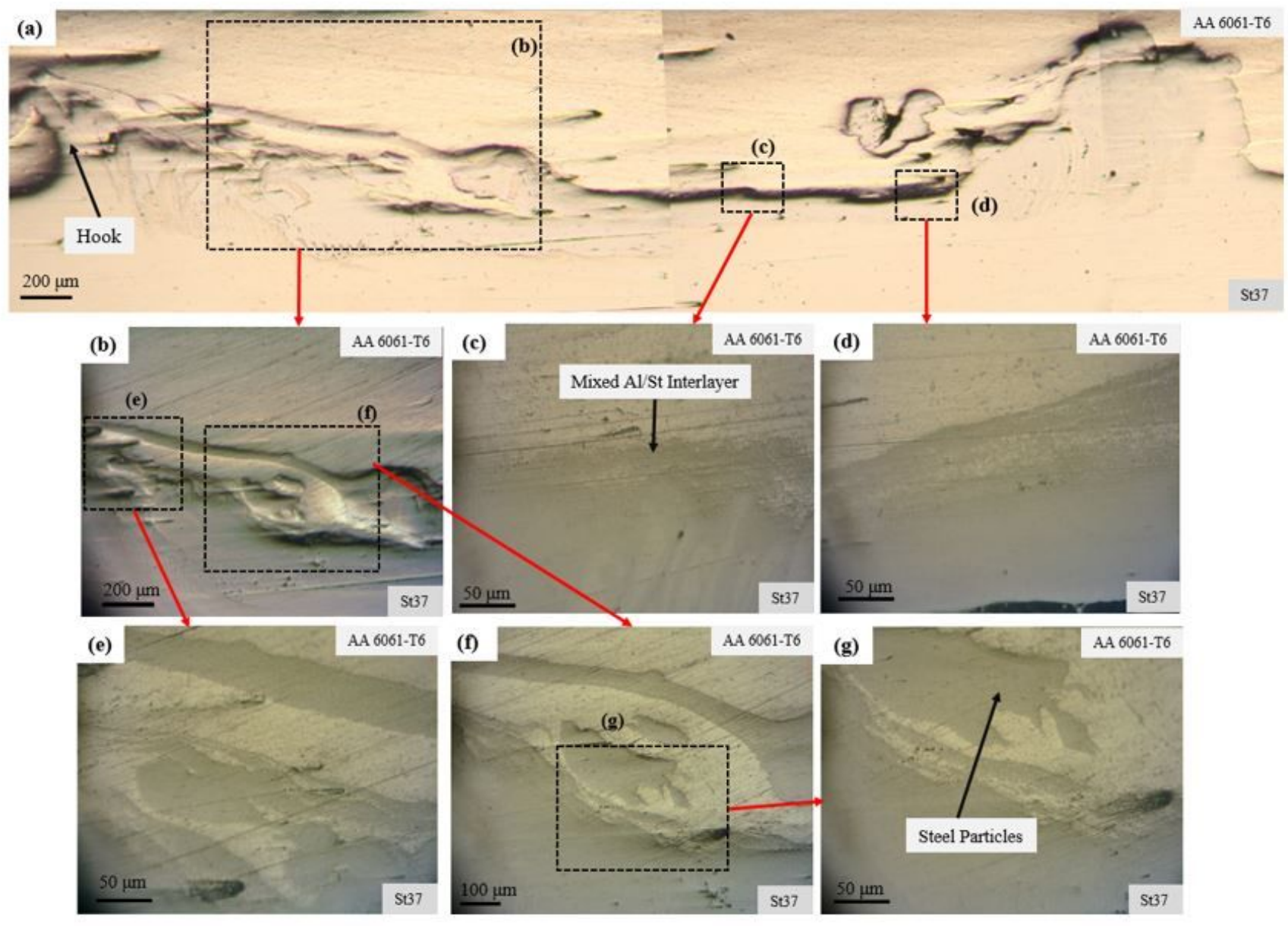

\section{Figure 5}

Optical microscope image of the transverse section of the specimen at (RS of $800 \mathrm{rpm}$ and TS of $25 \mathrm{~mm} / \mathrm{min}$ ). (a) The pin penetration zone in the steel layer, $(b, c, d, e, f, g)$ the enlarged areas from different parts of the Al/St middle layer 

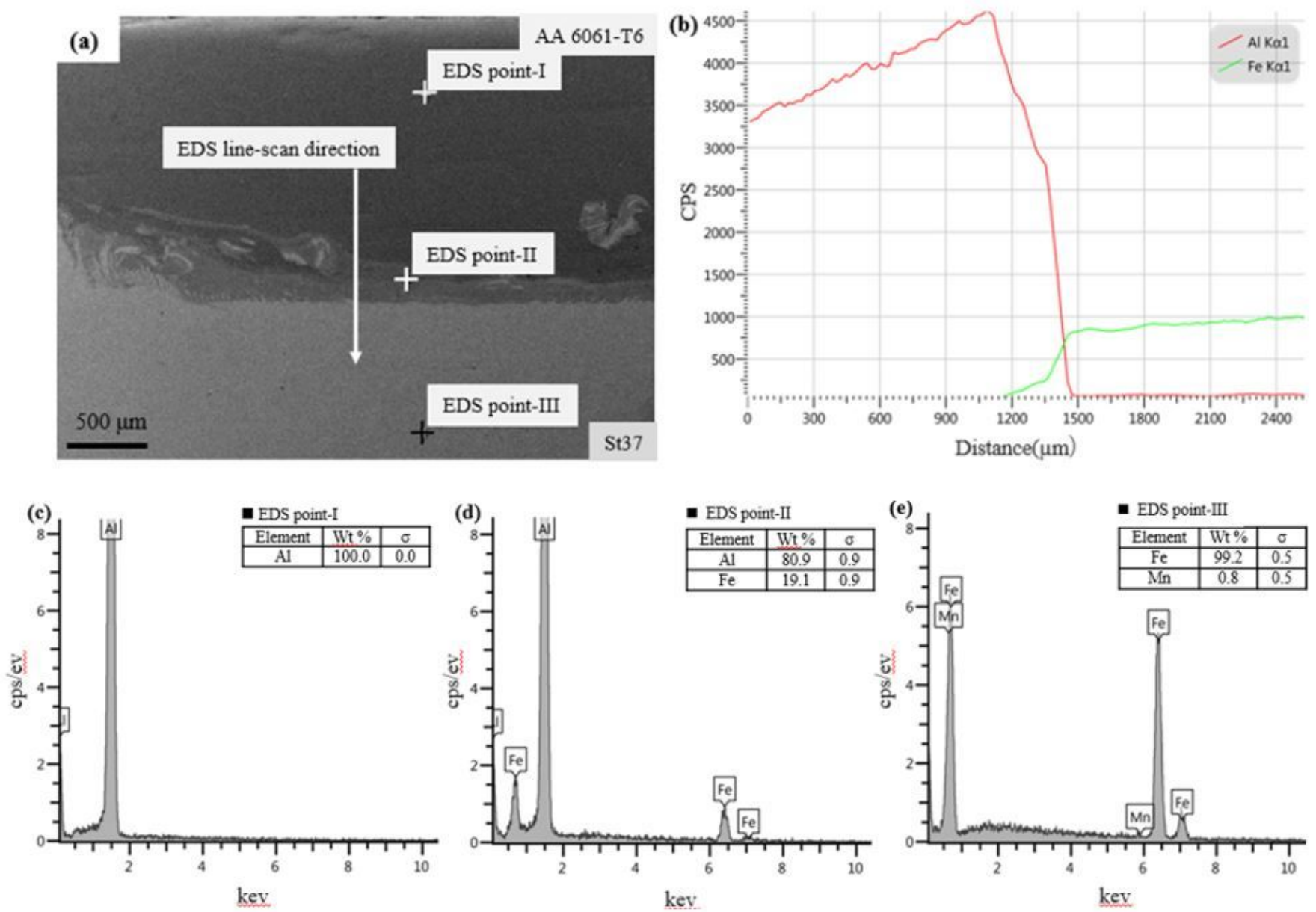

\section{Figure 6}

(a) The scanning electron microscope image from the cross section of the specimen at (RS of $800 \mathrm{rpm}$ and TS of 25 $\mathrm{mm} / \mathrm{min}$ ), (b) line scanning analysis, (c, d, e) the EDX analysis of points I, II III 

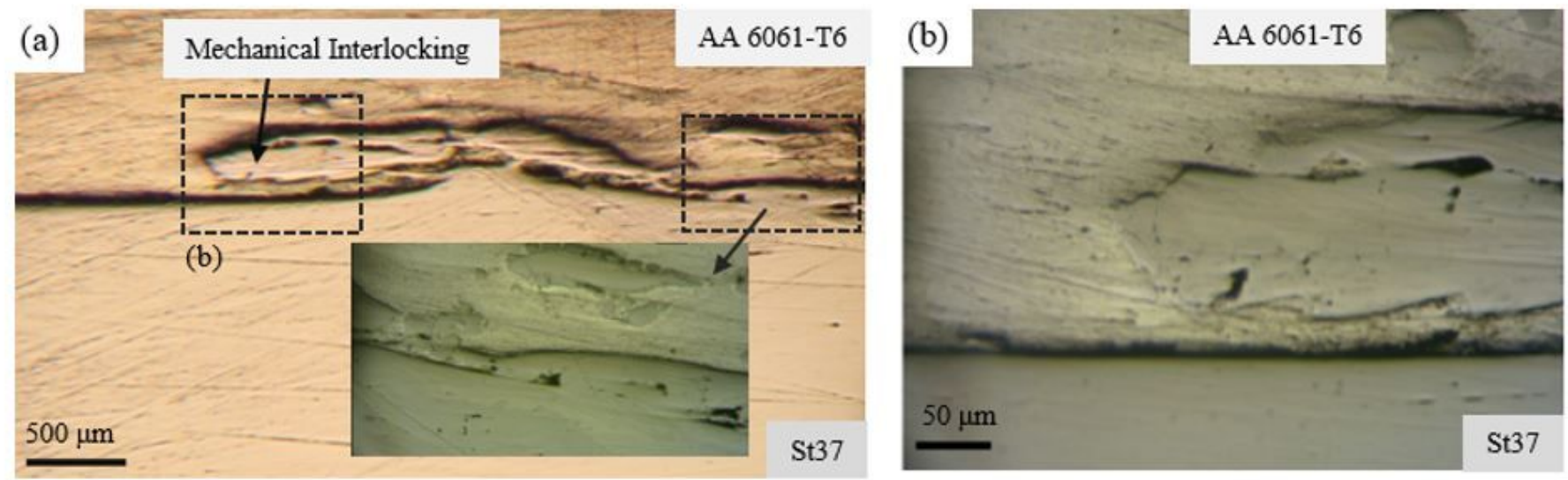

(c)

AA 6061-T6

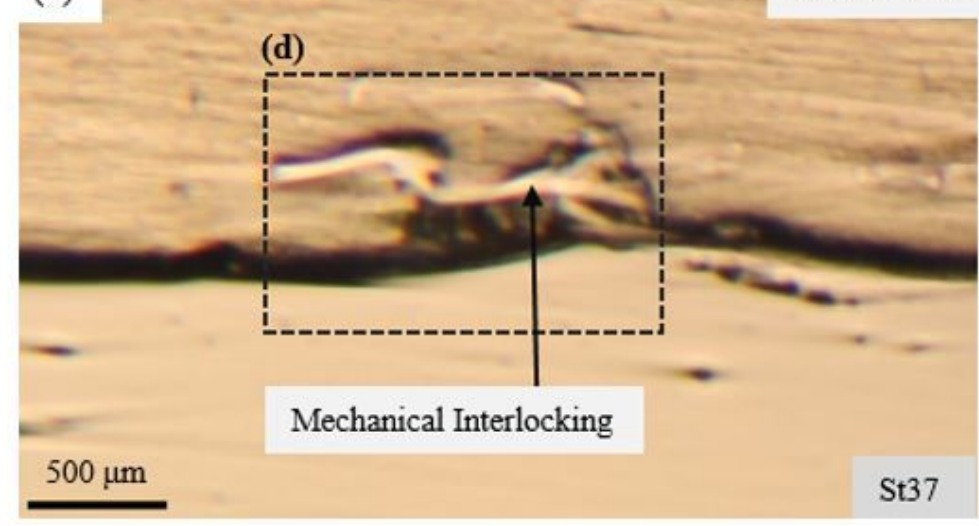

(d)

AA 6061-T6

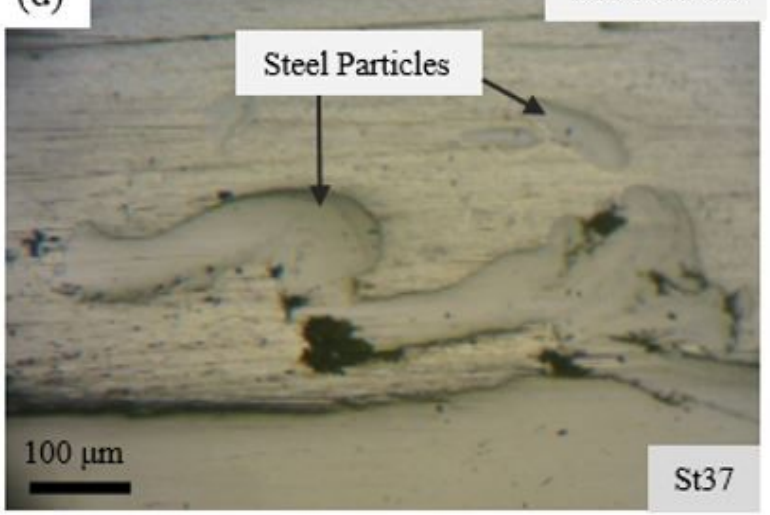

\section{Figure 7}

Cross-section macrostructure of clad-plate specimen, (a, b): RS of $1200 \mathrm{rpm}$ and TS of $35 \mathrm{~mm} / \mathrm{min},(\mathrm{c}, \mathrm{d})$ RS of 1000 $\mathrm{rpm}$ and TS of $35 \mathrm{~mm} / \mathrm{min}$ 

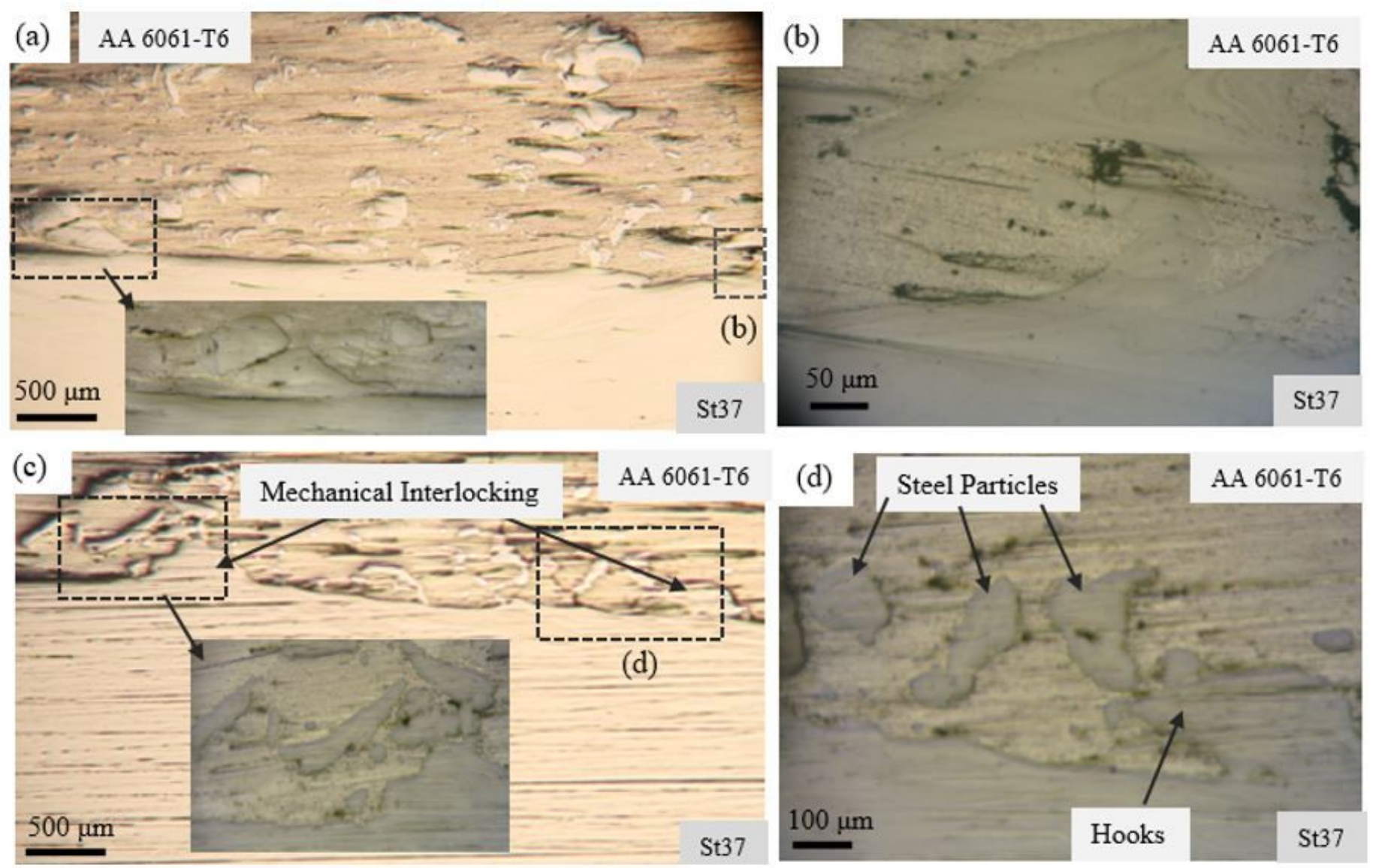

\section{Figure 8}

Cross-section macrostructure of clad-plate specimen, (a, b) RS of $800 \mathrm{rpm}$ and TS of $35 \mathrm{~mm} / \mathrm{min},(\mathrm{c}, \mathrm{d}) \mathrm{RS}$ of $800 \mathrm{rpm}$ and TS of $15 \mathrm{~mm} / \mathrm{min}$ 

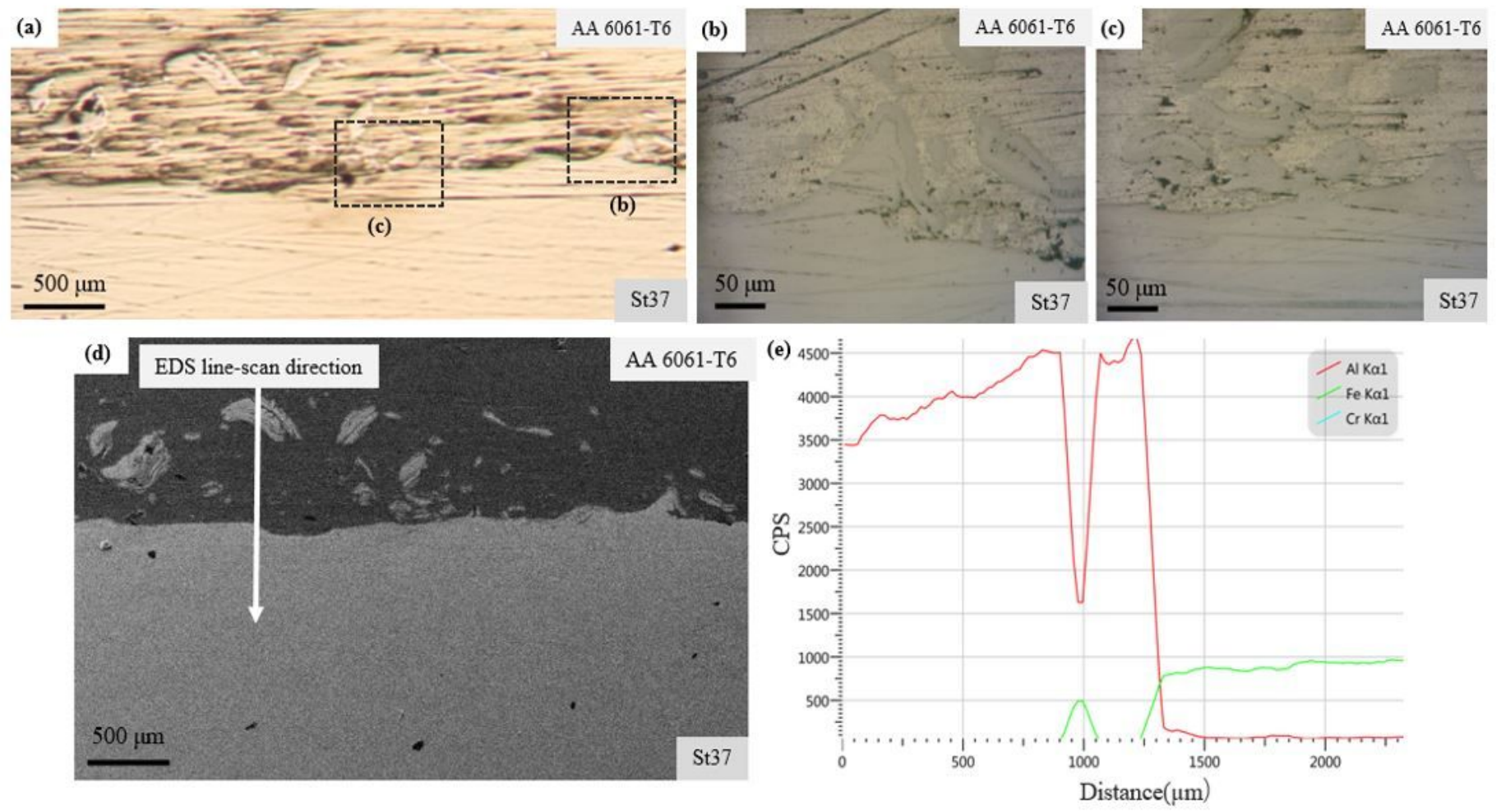

\section{Figure 9}

the scanning optical and electron microscope image of the cross section of the specimen at (RS of $1000 \mathrm{rpm}$ and TS speed of $25 \mathrm{~mm} / \mathrm{min}$ ). (a) The middle layer of the cladded specimen. (b) \& (c) Enlarged areas from different parts of the middle layer in image a. (d) the scanning electron microscope image from the middle layer. (e) The line scanning analysis in the direction shown in the image $d$ 


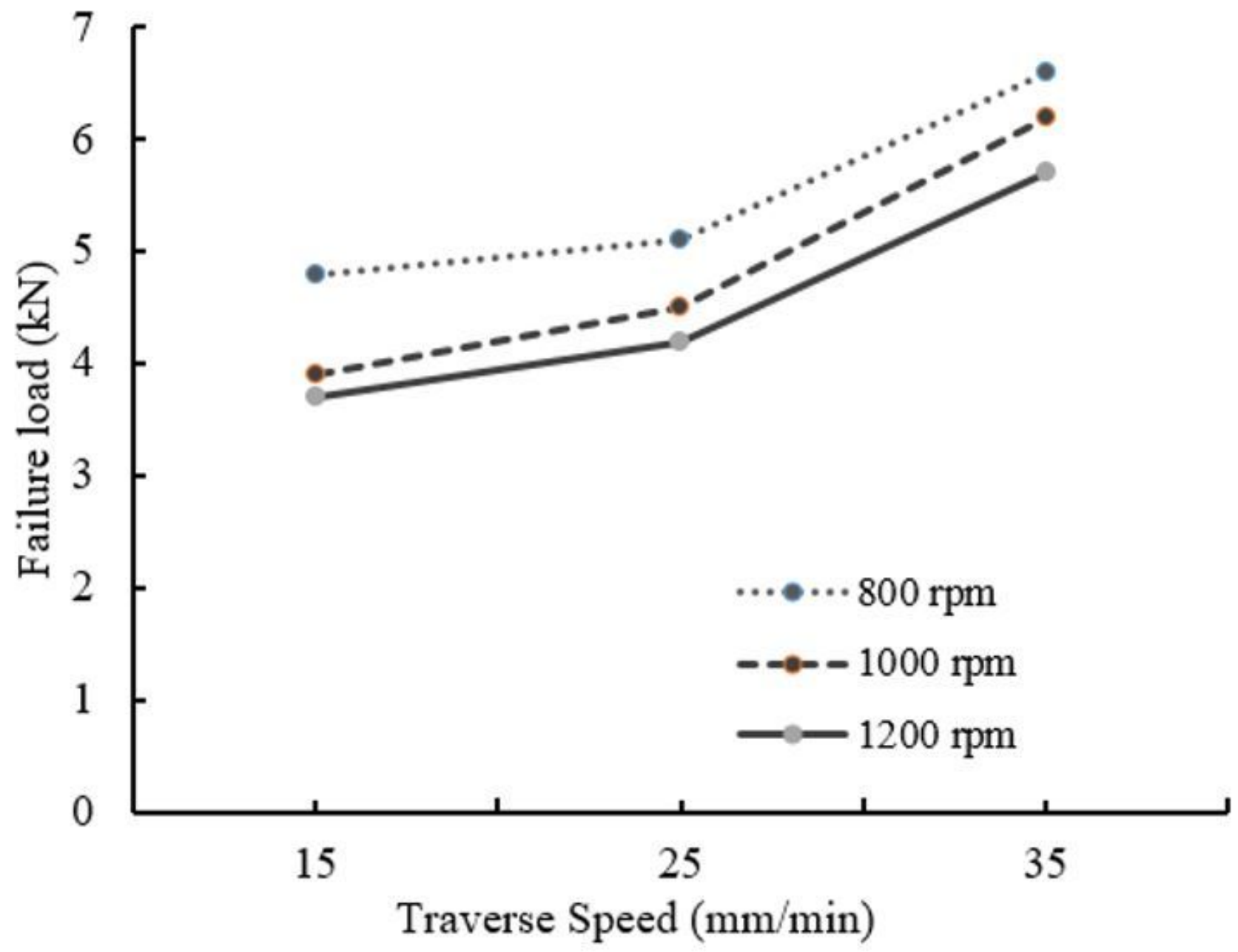

Figure 10

The shear strength of the cladding specimen for different rotational and traverse speed 


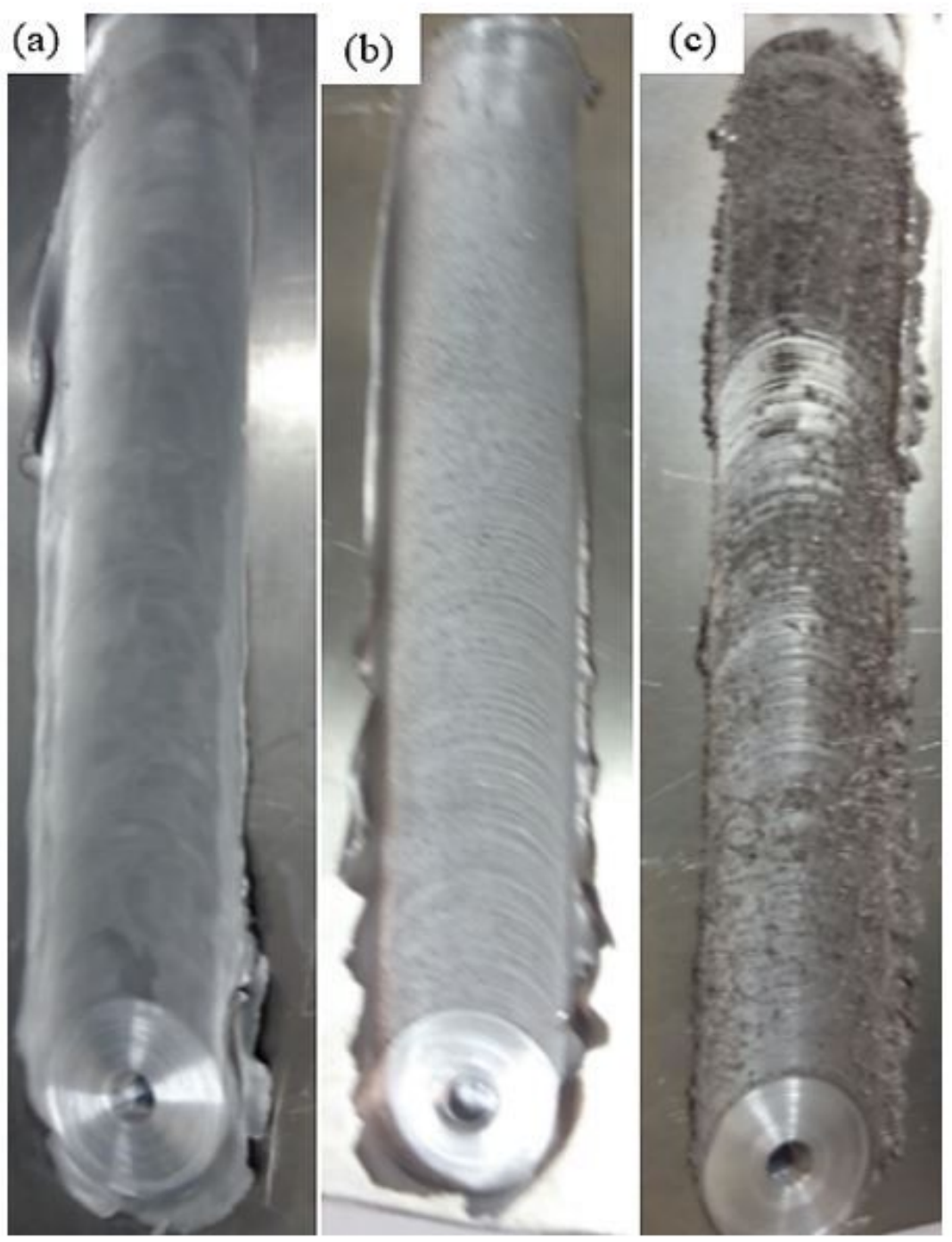

Figure 11

Surface flow of the cladded specimens at RS of $800 \mathrm{rpm}$ (a) TS of $35 \mathrm{~mm} / \mathrm{min}$, (b) TS of $25 \mathrm{~mm} / \mathrm{min}$, (c) TS of 15 $\mathrm{mm} / \mathrm{min}$ 


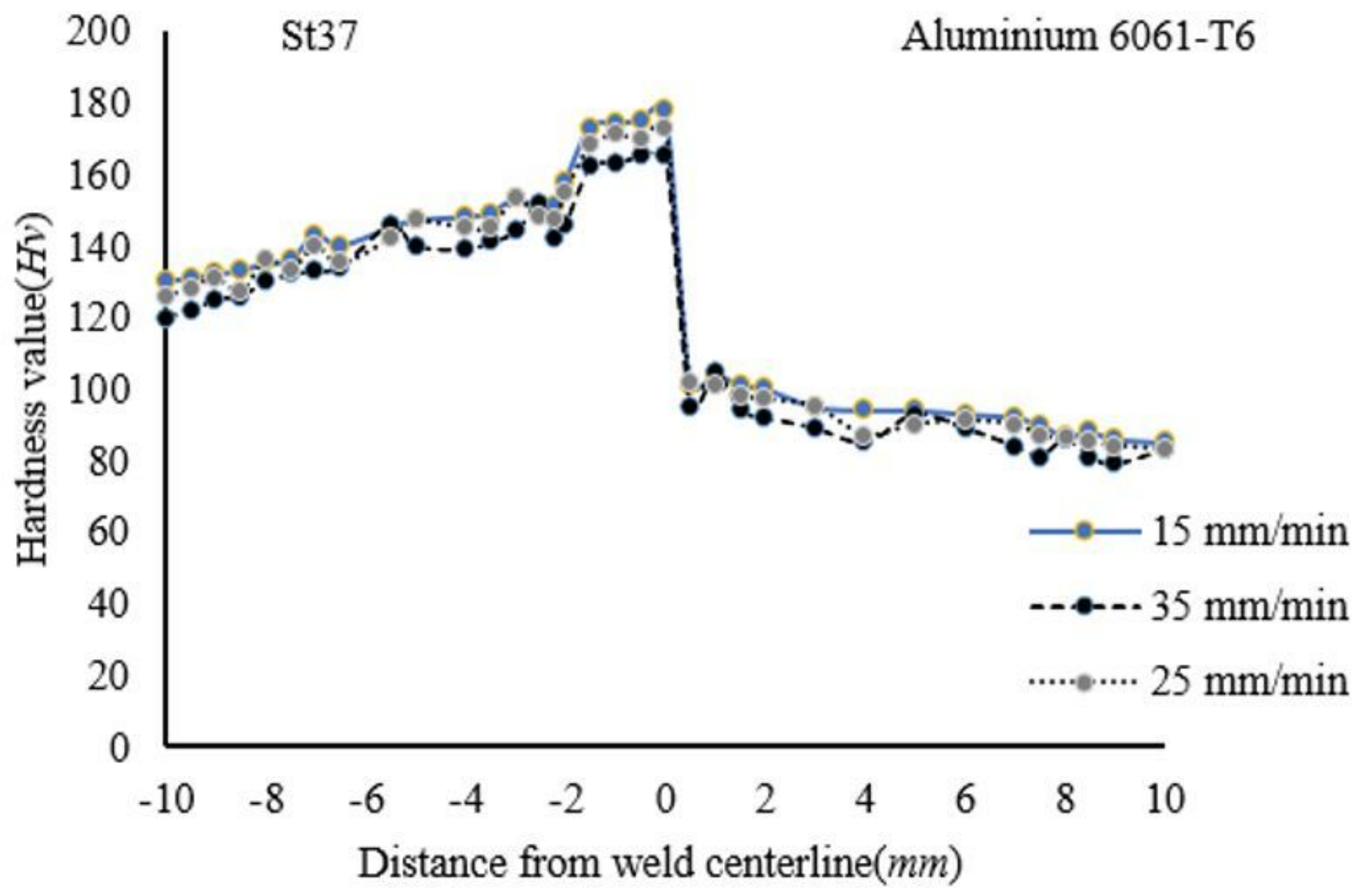

Figure 12

Distribution of hardness via distance from clad interface 